Orbis Tertius, vol. XXIII, nº 28, e089, diciembre 2018. ISSN 1851-7811

Universidad Nacional de La Plata

Facultad de Humanidades y Ciencias de la Educación

Centro de Estudios de Teoría y Crítica Literaria

\title{
Una opción por el teatro en el pensamiento de Saúl Taborda y Rodolfo Kusch
}

\section{Laura Casasola*}

* Universidad de Buenos Aires/ Universidad de Lanús, Argentina

Cita sugerida: Casasola, L.(2018). Una opción por el teatro en el pensamiento de Saúl Taborda y Rodolfo Kusch. Orbis Tertius, 23(28), e089. https://doi.org/10.24215/18517811e089 


\title{
Una opción por el teatro en el pensamiento de Saúl Taborda y Rodolfo Kusch
}

\author{
por Laura Casasola \\ (Universidad de Buenos Aires/Universidad de Lanús)
}

\begin{abstract}
RESUMEN:
Saúl Taborda y Günther Rodolfo Kusch, dos pensadores nacionales pocas veces pensados en conjunto por sus escasos puntos de contacto, son reconocidos por su obra filosófica e intelectual. Sin embargo, ambos desarrollaron una faceta artística, no por marginal menos significativa: el teatro de ideas. En este trabajo, se focalizará sobre dos piezas: "La sombra de Satán" de Taborda y "La muerte del Chacho" de Kusch. Se intentará demostrar el modo en que el discurso del deber y la praxis vital desatan un conflicto dramático que termina irrevocablemente en la tragedia. Finalmente, se puede conjeturar que ambos pensadores conciben al teatro como un hecho cultural que promueve la educación y concientización a partir de la puesta en escena de la vida.
\end{abstract}

Palabras Clave: Arte americano - Teatro de ideas - Vida - Deber - Metáfora vital .

\section{ABstract:}

Saul Taborda and Günther Rodolfo Kusch, two national thinkers rarely considered jointly due to the scarce common ground between them, are highly regarded for their philosophical and intellectual work. Nevertheless, they both developed a significant, though marginal, artistic side: the theatre of ideas. This paper focuses on two plays: "The shadow of Satan", by Taborda, and "The death of Chacho", by Kusch. It will attempt to demonstrate the way in which the discourse of duty and vital praxis unleash a dramatic conflict that will inevitably lead to tragedy. Finally, it can be inferred that both intellectuals conceive of theatre as a cultural event that promotes education and awareness arising from the staging of life.

KEYwORDS: American art-Theatre of ideas - life-duty-life metaphor .

\section{Dos ADVenedizos: Dramaturgia desDe los márgenes}

Saúl Taborda (1885-1943) y Rodolfo Kusch (1922-1979), dos pensadores nacionales pocas veces pensados en conjunto por sus aparentes escasos puntos de contacto, han introducido desde la periferia profundos cuestionamientos al proyecto modernizador de la Argentina del siglo XX. En la época de oro de la dramaturgia argentina, estos pensadores se inscribieron en una opción teatral originaria de campos intelectuales periféricos.

El joven Taborda, inflamado por las ideas de cambio y emancipación, presidió en 1916 el Círculo de Autores Teatrales. Esta agrupación fue el frente artístico de la "generación rebelde", luego refundida en la Fundación de Córdoba libre (1916) y la Universidad Popular (1917), todas ellas impulsoras de la Reforma de 1918. En la parte estética, denostaban la dramaturgia porteña (el sainete y el grotesco) a causa de la deformación del lenguaje y la creación de monstruos escénicos para convocar a las masas. En cambio, adherían a un arte reflexivo y minoritario, a un teatro de ideas cuyas tesis pretendían despertar la toma de conciencia y la actitud crítica del espectador.

Osvaldo Pellettieri en su Historia del teatro argentino en las provincias (2005), sólo alude a Saúl Taborda como un modesto miembro esta generación. Según el especialista, estos jóvenes provenientes de la elite cordobesa tenían una paradojal relación respecto de su sector social. Por un lado, utilizaban sus contactos con el poder político y la prensa, para obtener cierta visibilidad en la escena teatral local. Por otro lado, tomaban una postura crítica frente a la realidad inmediata y cuestionaban los principios ideológicos de la oligarquía. Pese a su exigua producción y escaso impacto en la dramaturgia nacional, concluye Pellettieri, "este fugaz movimiento propuso una auténtica búsqueda de articulación entre el campo teatral y la realidad política y social" (Pellettieri 2005: 144).

Las obras teatrales de Taborda fueron puestas en escena en las plazas provinciales con notable éxito: Juvenilia (1906), comedia en tres actos dirigida por Dietrich; El mendrugo (1916), drama a cargo de la 
compañía Muiño-De Bassi; El dilema (1916), comedia interpretada por Arrellano-Tesada; La obra de Dios (1916), drama estrenado por la compañía Rosich-Balestrini. Mientras que estas obras son inéditas, en 1916 se publicó La sombra de Satán. Episodio de la vida colonial con ribetes valleinclanescos [1909], "concebido como un drama literario -es decir, «irrepresentable»-" (Ferrero 1988: 23). Fuera del ámbito cordobés, el reconocimiento de Taborda en la literatura argentina y en el arte escénico es nulo: "Entre los dramaturgos tampoco podría ser considerado, naturalmente, desde que todas las Historias del teatro nacional que existen son en realidad crónicas del teatro porteño" (Ferrero 1988: 25).

Con respecto a Rodolfo Kusch, su tránsito por los círculos intelectuales ha sido subrepticio, pues no congeniaba con la intelligentzia europeizante del ámbito ilustrado y tendía hacia los pensadores nacionales, la intelectualidad periférica y el teatro independiente. Fue docente de Cultura y Estética, de Filosofía y Ética; colaboró con artículos para la prensa gráfica en medios tan disímiles como "El Mundo" y "La Nación", "Contorno" y "Sur". Tras su autoexilio jujeño, quedó definitivamente excluido del campo intelectual hegemónico. Sus últimos años, se dedicó al estudio de Antropología Filosófica y al patrocinio de eventos académicos situados en la región andina.

La obra teatral de Kusch contempla cinco piezas: Tango (estrenada por el conjunto Juan Cristóbal en 1957) y Credo Rante, ambas publicadas en 1958; La leyenda de Juan Moreira (estrenada por Francisco Petrone en el Circo Teatro Arena en 1958) y La muerte del Chacho (trasmitida por Radio Municipal en 1964), publicadas en 1960; Cafetín (inédita). La situación de Kusch en el campo literario argentino es semejante al de Taborda; el segundo tomo de la Historia de Pellettieri casi no lo menciona, cuando ha sido uno de los más salientes ingenios de la región norteña. En juicio del dramaturgo y poeta Roberto López Pertierra: "El arribo de Rodolfo Kusch a la dramaturgia nacional significó, para los demás, una herejía conceptual y formal. [...] Su producción teatral permanece casi ignorada, en un medio que entiende por vanguardia la apropiación de la experiencia ajena" (Kusch 2007: 825-832).

Kusch reflexionó acerca de la estética autóctona en varios ensayos, donde argumenta la legitimidad del arte oral como auténtico dispositivo dialógico americano: "Lo americano como espacial no se registra con la misma intensidad si no es en el género oral de expresión. [...] Y como no tenemos ninguna madurez estética, porque tampoco la tenemos en el plano social, nuestra verdadera expresión está en el terreno del arte primitivo, o sea el oral" (2007: 806-7). A ello agrega que es un inmejorable medio expresivo de la sensibilidad americana: "Y quién sabe si no habrá de repetirse, como ya lo hemos advertido en estas páginas, un arte de lo monstruoso en tanto registra el trasfondo geográfico y espacial, la violencia expresiva dentro de un espectáculo mágico que convierte al teatro en su principal vehículo y todo ello conteniendo ese estar biológicamente en cero, en lo humano y lo ameboidal de lo americano cautivo en el espacio" (2007: 814). A su vez, los dramas de Kusch solían estar acompañados por un importante aparato crítico de mano del autor. Un ejemplo es el Prefacio de La leyenda de Juan Moreira, donde expresa: "Ante todo [está] la sobriedad de recursos y una gran sinceridad estética, sin abandonar en ningún momento toda esa fealdad que exige el sentido bárbaro y salvaje del tema. Está implícito en nuestro ámbito pampeano un sentido trágico, que se resuelve formalmente con suma sencillez" (2007: 828-9).

Por otra parte, existe una segunda marginalidad, esta vez, hacia el interior de la producción de cada autor. Saúl Taborda y Rodolfo Kusch son reconocidos por su obra filosófica, gracias a una vasta producción y un sólido aparato intelectual. Sin embargo, ambos se inclinaron por una opción literaria, no por marginal menos significativa: un teatro reflexivo hacia lo exterior y metarreflexivo hacia el interior. Taborda explotó una vena ficcional juvenil y experimental, mientras que Kusch desplegó su faceta artística en época de mayor madurez y afianzamiento de su escritura filosófica. Ahora bien, esa marginalidad no es accesoria ni trivial, sino que supone ese repliegue que permite al pensamiento volverse sobre sí mismo y cifrar la totalidad desde la parte. Por eso, estas composiciones guardan una neta coherencia de sentido y una misma orientación ideológica con sus proyectos intelectuales: la devoción tabordeana del arte como máxima figuración de la vida natural, individual y colectiva; el posicionamiento kuscheano de una vida capaz de estar en el arte. 


\section{TABORDA: El ARTE DE LA VIDA}

En lo sucesivo, se desarrollará un análisis crítico de dos piezas teatrales, La sombra de Satán de Taborda y La muerte del Chacho de Kusch, con el objetivo de demostrar el modo en que discurso del deber y la praxis vital desatan un conflicto dramático que termina irrevocablemente en la tragedia. Taborda ha desarrollado un vasto derrotero filosófico alrededor del concepto vida y lo vital, pero aquí nos limitaremos a aquellos ensayos contemporáneos a su etapa literaria. Ya en su tesis doctoral La eximente de beodez en el Código Civil Argentino (1915), aparece una primera reflexión acerca de vida y norma:

[Las leyes que se apoyan en verdades absolutas] Invariables, como el principio mismo, desconocen el constante movimiento evolutivo de nuestra realidad, su eterno devenir, y en tales condiciones las sorprenden y revocan las sanciones de un legislador más sabio, más humano y más científico: la Vida (1915:7)

En el Prólogo de su autoría al libro Naranjo en flor (1918) de José de Maturana, Taborda expresa una verdadera arte poética de la vida:

Al arte tieso, pulimentado y encogido que se encerró en la torre de marfil, como la momia en el sarcófago, ha sucedido un
arte de carne y hueso que pasea con nosotros por las calles y por las plazas, que desciende con nosotros al fondo de las minas,
que penetra con nosotros a los talleres y a las fábricas, que corre con nosotros por los campos bajo el azote del viento y de la
lluvia y bajo el rigor del sol, que con nosotros sufre, que con nosotros ama, que con nosotros canta. El arte de la democracia
es, pues, el arte de la vida; y a la vida ha de referirse, en término último, de uno u otro modo, toda manifestación espiritual
que no quiera colocarse fuera de su tiempo y de su misión. [...] Poeta nuestro [Maturana], genuinamente nuestro, abreva
su inspiración en fuentes americanas. La vida seria y fuerte de las pampas seduce su optimismo; ella es en parte principal el
tema de su obra. (1918: 8-9 y 22)

El tercer referente ineludible es su primer tratado filosófico, Reflexiones sobre el ideal político de América, también de 1918, donde se enlazan vida y democracia:

La democracia es una concepción general de la vida y se refiere al proceso universal de la civilidad. [...] Hablar de democracia es significar el proceso adaptativo de la especie: es referirse al triunfo completo de la vida, de la vida no tan luego como feliz combinación físico-química, de la vida como órgano biológico, sino también de la vida que es fuerza y es medida, de la vida que es euritmia en el desarrollo corporal y es armonía en el cultivo del espíritu como en los púgiles del Ática, de la vida que se sabe afirmar por el esfuerzo y se proyecta por el alma; en una palabra, de la vida que es salud y es belleza. [...] El hombre es el sujeto de la vida. [...] La filosofía entera no es otra cosa que el pensamiento humano proyectándose constantemente sobre la condición del sujeto de la vida. [...] Ella [la democracia americana] reduce todos los valores a un solo valor llamado Vida y tiende con ella sobre los escombros del pasado el puente del Hombre. (2006: 144, 146156 y 160)

En el caso de La sombra de Satán, el móvil de acción es un dilema sintetizado por Adelmo Montenegro como una "dialéctica del amor y del deber" (1984: 13). En efecto, la obra pone en escena un tenaz romance entre dos jóvenes frustrado por el hostigamiento del deber religioso y político. El idilio representa el incontenible impulso de la juventud, un deseo carnal rebelde explicitado en el texto: "[Es] el viejo conflicto entre el amor y el deber. El uno nos atrae y nos seduce con sus falacias juveniles; el otro nos retrae, nos sujeta, nos gobierna y tiraniza. El uno es ensueño; el otro el despertar" (1916: 127)

Como procedimiento literario, el estado amoroso se cristaliza en metáforas de lo vital que remiten a la naturaleza, tal como las Sonatas valle-inclanescas aludidas en el subtítulo. Cuando es genuino, signo de "amor es la estrella"; si es ingrato, "las flores del jardín dan sus perfumes a la mano que las corta de la planta”; con el desengaño, "el invierno marchita las hojas y los pétalos para señalar con ellos el camino del olvido" (1916: $17,14$ y 82$)$.

Paulatinamente, de las imágenes de la vida natural brota un sensualismo epicúreo cuyos portavoces son los personajes seductores: primero, en el romance del juglar, donde se enuncia: "Dijo al Eterno una vez/ un bello clavel punzó:/ -Concédeme por favor,/ ser la boca de una mujer" (1916, 130); luego, en las diatribas de las brujas, se insinúa: “-Yo sé por qué brotan las flores en la primavera -Yo sé por qué hierve la sangre en las venas del macho cabrío [...] -Yo sé por qué mugen los toros y tiemblan las vacas [...]” (1916: 144/7); 
finalmente, en la voz de Daniel, se invita a vivir la primavera: "Primavera de ensueño,/ primavera gentil,/ primavera amorosa,/ yo te siento vivir" $(1916,153 / 6)$. Aun más, esta imaginería persiste en las didascalias de un autor con fuerte presencia -descriptivo, emotivo y valorativo-, como la que abre el acto III:

Noche de primavera propicia al amor y al ensueño. [...] Dionisíaca orgía de rosas y claveles que entreabren sus botones como bocas que implorasen mil ósculos de amor; de jazmines y de nardos que semejan cien copas caprichosas colmadas de nepente; de lirios como nieve que son cuellos de alabastro esperando la mano masculina que posee la caricia de íntimos espasmos; de azucenas que son cálices profanos levantados en herejes ofertorios de una misa de placer y de pecado. (1916: 140/1)

$\mathrm{Al}$ igual que el amor, el éxtasis místico se verbaliza con tropos de la vida natural como una sublimación de lo sensible o con una "idea de lo ecuménico, como expresión de un sentido concreto de la vida" (Monserrat 1956: 12-3).

La cohorte de palomas que revolotea sobre sus sienes [de Santa Teresa], sus manos que al unirse en la actitud de oración semejan el inventar de una magnolia, la delicadeza de sus albas mejillas, la sensualidad refinada de su nariz de aristocrática belleza, aquella boca descolorida que solo supo del beso de los amores divinos y aquellos ojos fatigados por inefables ensueños religiosos. [...] [Los ángeles] me allanan los sanderos siderales y tienden alquetifas de pétalos de flores, de rosas de Jericó, de olivos de Jerusalén, de lirios de Saharón. Hay, a lo lejos, un vislumbre de aurora que lo va llenando todo, poco a poco. Los cielos se cubren de alegría. Se oyen por doquiera los hosannas mientras subo, envuelta por un nimbo de palomas eucarísticas. (1916: 41/2 y 89/90)

Esta correspondencia entre amor y vida, conlleva su opuesto, deber y muerte. El filósofo Carlos Casali lo explica como la contraposición de "la pulsión desbordante de la vida con la tiranía del deber" (2012: 27). Para plasmarlo literariamente, Taborda apela al tópico -recurrente en el modernismo americano- de la amada inmóvil, una suerte de muerte en vida, vinculada con la enfermedad de amor. El de Alma es un drama alegórico al estilo medieval con una doble agonía: la lucha entre el bien y el mal; el tránsito entre la vida y la muerte. Desde el mismo título, el tenor confesional se hace ostensible con la sola mención de Satán, pero el problema es que su sombra se torna falaz y difusa, vaga por los recintos sagrados, tiene máscaras de santidad. A medida que avanza el conflicto, se desdibuja el idilio amoroso para acentuar la tensión entre misticismo y oscurantismo, la búsqueda de la contemplación divina entre los tormentos de la carne, cuyo clímax estalla en la escena final donde comparecen los coros de brujas y ángeles, la imagen de Satán y la de Cristo. Por último, tras las figuradas tentación y caída, se desencadenan la crisis y la catarsis, seguidas de la resolución trágica: la muerte física de la muchacha y la muerte de los ideales del amante. Como lo entiende Caturelli, el deber que lleva a la muerte es consecuencia de la opresión religiosa: "Las aclaraciones de Taborda (algunas de las cuales son blasfemas) intentan mostrar el conflicto entre el amor (la vida) y el deber; este último, resultado de una tiranía de la visión cristiana de la sociedad, termina por destruir a la vida" (1995: 21). Pero Casali más bien concibe al deber como el resultado de una moral antitética:

El conflicto entre la vida y el deber se realimenta de su propia estructura dualista: el propio deber -el Cristo- aparece como el mal -Satán- no bien evidencia la fuente que lo impulsa y le da sentido, la vida. Una moral que se alimenta de aquello mismo a lo que se opone no puede sino quedar atrapada en las redes de la autocontradicción. [...] En ese instante ingresa Daniel al recinto para presentarse como el salvador posible de Alma, un alma destruida por la contradicción que muere en el instante en que se entrega a la vida. (2012: 35$)$

Así como el amor se expresa en una figuración vitalista, los mandatos del deber se manifiestan en dos discursos: católico-conservador y laico-liberal. Por un lado, el ideario conservador está representado por el Padre Zenón en el ámbito religioso y por Salguero y Torrealba (con sus antecesores) en el ámbito político. Como aparato discursivo, el dogma religioso se articula con el dogma político a partir de las prácticas de coacción por la custodia del deber y sojuzgamiento por el abuso del poder. El escenario del claustro se carga de sus cualidades: el lujo, el refinamiento, la penumbra, la frialdad. Por su parte, el ideario liberal está representado por el Doctor Rodríguez en el ámbito científico y por Daniel en el ámbito político. Esta postura 
crítica rompe con la moral tradicional y se posiciona en los campos del saber, la medicina y la política, pero sus reivindicaciones se sostienen sobre todo en el plano de la acción.

Estos discursos poseen una lógica antagónica: uno diagnostica endemoniamiento, el otro enfermedad; uno prescribe los votos, el otro el casamiento; uno reivindica las lecturas exegéticas, el otro los libros parisinos; uno fomenta sumisión, el otro libertad. De ahí, la imposibilidad de concordia: "Conciliar tendencias tan opuestas, haciendo desgraciada a una hija mía, ¡nunca!” (1916: 109). Desde luego, este es el discurso al que adhiere el autor, conforme la corriente contemporánea que María Pía López denomina vitalismo libertario: "La vida no es aquello que puede ser aceptado con conformidad o festejado en su mesura, sino que debe ser emancipado" (López 2010: 12).

Finalmente, se establece un vivo diálogo entre los acontecimientos de la Historia argentina y la vida de las comarcas del interior: De un lado, la tiranía monárquica y la rebeldía republicana cifran la disyuntiva civilización o barbarie. Del otro lado, la cultura popular se realiza en la sabiduría experiencial (los brebajes curativos, los consejos maternales), los relatos tradicionales (la pastorcilla, el trovador), los rituales familiares (la ceremonia de entrega de las trenzas, el apresto del vestido de fiesta). Pero ambas perspectivas convergen, pues el germen de la Revolución de Mayo se inscribe en la herencia facúndica: "La voluntad de Mayo, que, en cuanto hecho histórico, traduce la voluntad de ser inherente a la comunidad política argentina. [...] A Taborda le atrae lo facúndico no desde el punto de vista biográfico, sino como la realidad 'esencial y perviviente' que Facundo Quiroga encarna" (Monserrat 1956: 15 y 27).

\section{KUSCH: LA VIDA EN EL ARTE}

Así como para Taborda la dramaturgia ha sido uno de los canales privilegiados para la difusión de su pensamiento nacional, Rodolfo Kusch optó por el mismo medio expresivo con igual propósito. Sobre los años '60, el filósofo desarrolló una auténtica poética, donde el arte teatral es el vehículo óptimo para la formulación de un pensamiento aún carente de categorías:

\footnotetext{
Es indudable que lo teatral participa de la cualidad de lo absolutamente vital. Si la creación estética supone un proceso que parte del artista, como ente vital, y apunta hacia algo móvil, como lo es la obra la poesía dramática agrega a esa inmovilidad, nuevamente, la vida. Una escultura o una pintura son productos inmóviles. Representan una estabilización de las vivencias estéticas porque se han convertido en cosas que sólo aparentan lo vital. Pero la poesía dramática brinda la posibilidad de representar la vida mucho más allá de la apariencia. Si en otros terrenos se trata de modelar la piedra o combinar colores, en la poesía dramática se modela estrictamente sobre la vida.

Resulta un lugar común decir que lo teatral resume todas las otras artes para superarlas. Pero es interesante hacer notar que esta superación se realiza precisamente porque lo teatral y la vida se conjugan parejamente, de acuerdo con leyes similares o, más bien, con una similar falta de legalidad. Las leyes que ordenan el existir y existir significa ex-sistere o sea estar fuera del ser, comprometido hondamente con la vida. El mismo compromiso lo advierte Ernst Cassier para el teatro cuando afirma que "la poesía dramática descubre una nueva amplitud y profundidad de la vida". (2007: 817)
}

Con la misma euforia, el ensayo "Traición o cultura", que acompaña a la edición del '60, agrega: "Nuestra verdad está en el charco y no en la traducción de la Divina Comedia, así como está en la pista y no en la caja escénica, está en los bajos fondos y no en los hogares pomposos y está en la ignorancia del campesino y del indio, porque esta supone la sabia actitud de desconocer el juego estéril que se realiza en las ciudades" (2007: 590). Pero en el Prefacio de La muerte del Chacho, última obra publicada en vida, asoma un dejo pesimista: "Desgraciadamente el horizonte expresivo de nuestro teatro se halla muy limitado, no sólo porque se lo toma como un oficio adquirido con sus leyes cerradas y esotéricas, sino también por una reiterada ignorancia de nuestra gente de teatro referente a su situación de nacido en América" (2007: 651-2). Es notable el modo en que esta litigante melancolía impregna la totalidad de la obra: la lucha de Kusch por crear un teatro americano es tan vehemente como la de La Purinca por despertar al pueblo sometido y tan pueril como la del Opita por cosechar maíz en el llano. Aun así, estos personajes representan el "hombre ligado a América, con su extraño 
modo de ver el mundo" (2007: 651). Representan, en una palabra, la resistencia: la vida que está siendo en el arte.

Kusch, como Taborda, utiliza el procedimiento de la metáfora vitalista por medio de referentes naturales, el yuyo y el maíz, pues “interpreta el mito desde sus raíces vivenciales” (Pérez Martín 1982: 15-6). Estos objetos operan la mediación simbólica por la cual "una comunidad actualiza sus sentidos (presiona) y los reconoce como propios (impresiona)” (G. Gazquéz 1989: 24). El Opa, gestor cultural, exalta la vitalidad del yuyo, pero lamenta su fragilidad:

No estaría mal ser como yuyo. Pero los de abajo tienen algo más. Los yuyos tienen todo esto... Las hojitas (señala con el dedo.) Un tallito largo, un cuerpo... Míralo (Se lo muestra.) Míralo pues... Está fresquito [...] ¿Por qué se mueren todos? [...] Podríamos ser fuertecitos... (Mira a su alrededor, ve la planta estilizada). Como ellos... (Señala el maiz. Agrega asombrado.) Tan hechito el maíz. (Infantil.) Es el rey de los yuyos... (Mira a los que tiene a sus pies.) Estos son los opas (2007: 655)

Desde el discurso del Opa, los yuyos simbolizan la nimiedad del pueblo oprimido y el maíz, su intento de superación. Por prepotencia ajena o por impotencia propia, los yuyos son siempre pisoteados y lacerados; pero el Opa asume una actitud mediadora: "Mirá lo débil que es el yuyito y vive" (2007: 657-8). La visión distorsionada del Opa ve maíces en los simples yuyos: “([...] Mientras les da un yuyo.) Tomá, este maicito de las cumbres... Para que sean buenos" (2007: 663-4). Por su parte, el personaje del Juancho comienza con una postura derrotista: Perdida la guerra, trabaja la huerta de maíces que sembró la esperanzada Hembra en su ausencia; los terrones, la sequía y las plagas la asedian y su semejanza con cristos crucificados anuncia su destino. En contraste, los Hombres esperan volver a las armas y el Pueblo peregrina al son de sus lastimosas vidalas.

En el tercer cuadro, aparecen Peñaloza y Victoria. Él atraviesa un dilema interior y examina su deber como caudillo: resistir con la provincia o pactar con la nación; batir o entregar la lanza. Como en la obra de Taborda, los fantasmas de sus muertos toman la palabra para guiar su proceder. Ella, irresoluta, expresa sus vacilaciones con tropos naturales: "Vamos a hacer una nueva hacienda, como nunca se ha visto aquí. [...] (Súbitamente a punto de llorar, pero con fuerza.) No quiero seguir así. Volvamos a los llanos. Eso era vida" (2007: 671-2). Irrumpe el Opa: "Que linda lanza. (Pausa.) Es como un yuyito muy grande y muy maduro... pero nosotros somos blanditos... ¿No, Chacho?... Como cuando despunta el maíz y se lo quema la helada... (Pausa.) Tratá de cuidarla"; y Chacho concluye: "Esta lanza me maldice la vida" (2007: 674-5).

Entre las mujeres, se impone el discurso subversivo de La Purinca, la bruja guerrera (Tschudi 1974) cuya beligerancia afirma lo autóctono, lo bárbaro, lo facúndico como única resolución posible a la disyuntiva sarmientina:

Macho y hembra son la guerra, los cerros y las quebradas son la guerra, el cielo y la tierra. Hasta los yuyitos del Opa son la guerra. (Pausa.) ¿Te crees que uno se puede pasar así, sin hacer nada en el ranchito, sólo pa' morir en la cama?... Todo es macho y hembra... Llastay y Pachamama se juntan pa' darnos los animales y maíz" (2007: 677).

A su vez, la Hembra impele a la resignación de la vida pedestre: “¿Has visto las mazorcas? Ya están maduras para juntarlas y guardarlas para el invierno". Pero el Macho entiende que "la cosecha es cosa de hembras" (2007: 679). Para Norma Pérez Martín, este episodio posee connotaciones simbólicas: la huertita como "lugar sagrado" y el Lagarto como "lo diabólico" representan los “elementos mágicos y demoníacos" de la cultura indígena (Pérez Martín 1982: 12).

Cuando Chacho depone las armas, salen a escena las figuras de mando que buscan imponer la civilización: el gobernador y el militar. La extranjeridad de estos personajes se hace ostensible en el desconocimiento de los códigos comunales: “¿Ve? Dice que es maíz, pero no es más que yuyo seco y podrido” (2007:682). Pero el Opa invierte sus jerarquías con el imaginario comunal: “¿Ve? Los yuyitos son verdes... Jesús los hizo verdes. [...] Son verdes porque son pobres..." (2007: 683). Detenido Juancho por instigador, el Pueblo se une para ayudar a la Hembra con la cosecha y advierten que saquearon su huerto: "-Han robado las mazorcas. -Aquí ha 
quedao una. (La recoge. Al hacerlo se desprenden los granos.) -La más seca... -Parece tiempo de guerra" (2007: 688). Indignada, La Purinca desata el ritual mitico que convoca a la comunidad:

Les van a robar la hacienda y se van a pudrir de miedosos. Al Chacho lo vamos a tener que hacer nosotros. [...] ¿Van a esperar que el Chiqui les devore los sesos y les coma el hígado? Se van a quedar flacos y secos como un hueso, como para tocar la quena en un cementerio. Parecen opas, opas, opas. (Grita.) Yo tengo el alma del Chacho, malparidos. ¿Quieren vivir? ¡Griten! ¡Maten!” (2007: 690-1).

Ante la presión del Pueblo enfebrecido, le devuelven la lanza y el Chacho anuncia: “iQué sea pues! (Clava la lanza en el suelo. La contempla.) Ojalá crezca como el maíz”. Entonces, el Opa experimenta su anagnórisis:

Entregaste la lanza pero la volviste a usar... (Dulce.) ¿No ves que es como un tallo demasiado madurito para nosotros?”; “No!... Es mía... mía (Grita.) ¡A Ahora soy un montonero! (Rie, gozoso.) Me decían opa porque no tenía lanza... Ahora ustedes son opas. (Pausa. De pronto comprende el alcance de lo que ha dicho. La cara se le ilumina. Ve a todos como hermanos.) Podemos hablar... porque somos opas... (Sonríe.) Opitas... (Pausa. De pronto grita, levantando los brazos) ¡Resuciten!... ¡Resuciten!”. (2007: 699)

En sexto cuadro, ocurre uno de los más significativos episodios: El Opa, devenido en chamán, divide sus yuyitos en azules y montoneros y juega a la guerra como si fueran fantoches. El dramaturgo apunta: "Hay una estrecha relación entre lo que hace el Opa y las imágenes de la pantalla. Se diría que el Opa maneja la guerra con sus yuyos y cada movimiento de éste se agranda atrás para dar una sensación épica y heroica" (2007: 703). Esta técnica de teatro dentro del teatro permite, a partir de la metáfora vital, poner en escena lo irrepresentable y anticipar los próximos acontecimientos, pues los yuyos terminan pisoteados por los mismos montoneros que han de ser vencidos:

¡Este es el Juancho! (Pausa. Los otros se sorprenden.) Con los dos bracitos como como Jesús (Pausa.) Porque vos te vas a morir... Todos...Y van a ser como yuyos (Silencio.) Porque somos como la chalita ¿saben? Cuando está madura tiene dos bracitos abiertos... como los del padre-cura cuando da la bendición o del mismo Jesús cuando está en la cruz. (Pausa.) Y morimos y somos chala. Los montoneros que murieron están aquí. [...] Somos como un maíz... pero no nos dejan madurar. Eso solo quise decir. Por eso no quería la guerra, Chacho. Aunque vayamos a la guerra terminamos así... con los bracitos abiertos. [...] Si por lo menos llegáramos a ser semillas, ya no habrá tanto yuyo inútil, Chacho. (2007: 709)

En el cuadro final, sobreviene el "sentido trágico" que caracteriza al teatro kuscheano. En el último diálogo entre Peñaloza y Victoria, los avatares de la vida aparecen una vez más metaforizados con los tropos de naturaleza, porque el arte, parafraseando al dramaturgo, toma su modelo de la vida:

Victoria. -Vamos a Chile. Desde ahí recomenzaremos la lucha. Habrá otras provincias que se nos unan...

Peñaloza. $-¿$ Seguiremos segando yuyos?...

Victoria. -Volverán a crecer.

Peñaloza. -Claro... segarlos para que crezcan.

Victoria. -¿Acaso, la guardia los va a respetar?

Peñaloza. -Siempre quedará alguno que sabrá esperar...

Victoria. -¿El Opa? (Silencio.)

Peñaloza. -Quizá. Debe ser difícil saber lo que él sabe y llevarlo tan adentro.

Finalmente, tras la muerte a traición del "sucio montonero", el Opa sigue con vida gracias al Pueblo. Entre el espanto del espectáculo bárbaro de la decapitación, se anuncia un porvenir abierto con la metáfora vital de la semilla:

(De pronto, el Opa se desprende del grupo, saca su mazorca y le quiebra la punta, mientras va diciendo con expresión infantil:) Esta es la cabeza del Chacho ¿ven? Ahora se ha muerto mi barro porque ya no daba más. La cabeza del Chacho era pesada... ¡Volvamos al polvo! ¡No habrá más montonera!... Ahora somos como los granitos de chiquititos... Estamos muertos... ¡Muertos! Ya no somos más que chalita podrida y seca... (Pausa. Encuentra algo.) ¡Miren! (Alegre.) Una semilla... (Sigue buscando, mientras todos lo rodean.) Otra... otra... ¡Cuántas! (Contempla a todos). Semilla 'e yuyo... semilla 'e yuyo... (2007: 716) 


\section{Conclusiones}

En este trabajo, se ha demostrado el modo en que el discurso del deber y la figuración vitalista traccionan un conflicto dramático que termina irrevocablemente en la tragedia: el deber conservador que ahoga las primicias de la vida amorosa en Taborda; el deber centralizador que arranca los frutos arraigados a la vida comunitaria en Kusch. El lenguaje teatral es el medio expresivo óptimo para verbalizar este ideario: el arte tabordeano que se expresa en la metáfora de la vida natural, individual y colectiva; la dramaturgia kuscheana que exhibe la vida misma que está siendo en el arte.

El proyecto literario de ambos autores se imbrica en la historia de los pueblos, no así en la Historia oficial: Kusch se inspira en la "experiencia popular", Taborda en la "vida colonial". Su rebeldía contra el orden establecido toma forma en una estética facúndica como resolución de la disyuntiva civilización o barbarie: el arte es para Kusch "una manera herética de encontrar dentro de lo bárbaro a la civilización" (2007: 788) y según Taborda "el Sansón de la barbarie ha derribado el templo" (2006: 58). Estos pronunciamientos artísticos contemporáneos a la escritura de ficción guardan coherencia con el concepto de facundismo que impregnará la obra filosófica ulterior de ambos pensadores. De ahí que el "genio nativo" se realiza en el "arte indígena”.

Finalmente, se puede conjeturar que ambos pensadores conciben al teatro como un hecho cultural que promueve la educación popular y la toma de conciencia a partir de la escenificación de la vida. El teatro es un medio de expresión de ideas, de pensamiento, de filosofía, que es educativo en el sentido amplio del término: guía, conduce, cuida, alimenta. En palabras de Jorge Dubatti, el teatro kuscheano es "una puesta en drama" y "una puesta en praxis" de su pensamiento (2016: 134). Es también un mecanismo dialógico capaz de interpelar al espectador, de despertar en él preguntas, de sacudir las certezas del positivismo y de denunciar las frivolidades de la cultura extranjerizante. Y, por último, es una forma de mediación educativa a través de la representación de la vida, cuyo sentido trágico de fondo busca las formas adecuadas para mostrarnos a nosotros mismos, para reconocernos y para transformar la realidad americana.

\section{BIBLIOGRAFÍA}

Casali, Carlos (2012). La filosofía biopolitica de Saúl Taborda. Remedios de Escalada, Ed. Universidad Nacional de Lanús.

Caturelli, Alberto (1995). El pensamiento filosófico de Saúl Taborda: Del anarquismo al tradicionalismo hispánico. Córdoba, Fundación Veritas.

Dubatti, Jorge (2016) “El teatro de Rodolfo Kusch Tasat: Un teatro liminal de investigador-artista” en José A. y Pérez, Juan Pablo (coords.) Arte, estética literatura y teatro en Rodolfo Kusch. Buenos Aires, Imprenta Coop. Chilavert.

Ferrero, Roberto (1988). Saúl Taborda. De la Reforma Universitaria a la Revolución Nacional. Córdoba: Alción.

González Gazqués, Gustavo (1989). “«Cultura» y «Sujeto cultural» en el pensamiento de Rodolfo Kusch” en G. González Vazquéz - E. Ascuy, KUSCHy el pensar desde América. Buenos Aires, García Gambeiro.

Kusch, Rodolfo (2007). Obras completas. Tomo IV. Rosario, Fundación Ross.

López, María Pía (2010). Hacia la vida intensa. Una historia de la sensibilidad vitalista. Buenos Aires, EUDEBA.

Monserrat, Santiago (1956). El humanismo militante de Saúl Taborda. Colección Extensión universitaria N 86, Instituto social. Santa Fe, Universidad Nacional del Litoral

Montenegro, Adelmo (1984). “Ensayo preliminar” en Saúl Taborda. Buenos Aires, Ediciones Culturales Argentinas.

Pellettieri, Osvaldo (2005). Historia del teatro argentino en las provincias. Tomo I. Buenos Aires, Galerna.

Pérez Martín, Norma (1982). "La muerte del Chacho" de Roberto Kusch. Colección Ensayos Breves N8. Tucumán, Centro de Estudios Latinoamericanos. 
Pertierra, Roberto (2007). “Entorno al teatro de Rodolfo Kusch” en R. Kusch, Obras completas. Tomo IV. Rosario: Fundación Ross, pp. 825-832.

Taborda, Saúl (1915). La eximente de beodez en el Código Civil Argentino -Tesis doctoral-. Córdoba, Bautista Cubas. Taborda, Saúl (1916). La sombra de Satán. Córdoba, Bautista Cubas.

Taborda, Saúl (1918). "Prólogo" en José de Marturana, Naranjo en flor. Buenos Aires, Cultura Argentina, pp. 7-32.

Taborda, Saúl (2006). Reflexiones sobre el ideal politico de América. Colección Pensamiento Nacional e Integración Latinoamericana. Buenos Aires, Grupo Editor Universitario.

Tschudi, Lilian (1974) Teatro argentino actual, Buenos Aires, García Cambeiro. 